\title{
2
}

\section{Chinese College Students Seeking Psychological Help From Professionals-Rationally Should but Emotionally not?}

\author{
Haiping Wanga, Yan Ruth Xia
}

\begin{abstract}
The purpose of the present research was to investigate the predictors to Chinese college students seeking psychological help from professionals. By surveying 1,408 Chinese college students at five universities in mainland China, the results showed that among the factors examined, problem severity and help-seeking attitudes directly predicted help-seeking intention, while gender and subjective norms had a significant effect on college students' professional psychological help-seeking intention through help-seeking attitudes. Overall, the model explained $25 \%$ and $38.0 \%$ (for half- 1 and half- 2 data sets, respectively) of the variances of help-seeking intention. The results indicated that mainland Chinese college students rationally knew that they should choose to seek such professional help when the problem got severer enough, although they were emotionally reluctant to seek professional psychological help due to negative subjective norms around them. The implications and limitations were discussed.
\end{abstract}

\section{Keywords}

College students, help-seeking, predictors

Many studies found that college students prefer to seek help from informal rather than formal professionals (Benson 1990; Boldero and Fallon 1995), and this tendency is more obvious among minority student groups, especially among Asian students including Chinese college students (Kim 2009). Mainland China has adopted policies that aim to enhance college students' mental health (Ministry of Education 2001). The profession of counseling and psychotherapy has been growing rapidly and the number of counseling centers and counselors has been growing. The majority of the universities and colleges established their on-campus counseling services. In spite of the increased services, many Chinese college students with mental health issues still do not consider seeking professional psychological help as a way of dealing with their challenges (Chang 2008). It warrants research on factors that prevented students from choosing professional psychological help.

\section{LITERATURE REVIEW}

A growing body of research in recent years has been devoted to identifying psychological, social, and

\footnotetext{
aEast China Normal University, China

bUniversity of Nebraska-Lincoln, USA

Correspondent Author:

Haiping Wang, No. 103, 585 BinHu Road, Songjiang Xin Cheng, Shanghai, China, 200041
} 
environmental factors associated with help-seeking. These research were mainly based on two leading theories, Anderson's (1995) socio-behavior theory and Fishbein and Ajzen (2010)'s theory of reasoned action (TRA). As a result, they identified many factors related to college students' professional help-seeking decision.

Level of problem severity as a way of measuring the help-seeking needs influences an individual's intention to seek professional help (Carlton and Deane 2000; Cepeda-Benito and Short 1998; Cramer 1999; Pugh 2002). Those considering seeking help reported greater levels of problems and more positive help-seeking attitudes than those not considering seeking help. However, the exact nature of this relation remains unresolved. Several studies suggested that more serious problems were related to stronger intentions to seek help (Cepeda-Benito and Short 1998; Cramer 1999). On the other hand, Deane, Wilson, and Ciarrochi (2001) found that individuals reporting the highest levels of suicidal ideation reported the weakest intentions to seek help from others, and were more likely to report that they would not seek help at all, as compared with individuals reporting lower levels of suicidal ideation. This study suggested that, for some problems, when distress was high, help-seeking intentions were suppressed. Researchers called this effect help-negation effect (Yakunina et al. 2010). Some other studies argued that problem severity was not meaningfully related to help-seeking intentions (e.g., Carlton and Deane 2000; Kelly and Achter 1995). Evidently, the relation between problem severity and help-seeking intentions is not conclusive and warrants further examination.

Help-seeking attitudes was found significantly predicting help-seeking intention in many studies. This relationship has been documented in the college students' help-seeking research (Bagley 2011; Wong 2010). Studies using predictors in addition to help-seeking attitudes revealed that help-seeking attitudes suppressed the effects of other factors and appeared as the only significant predictor of help-seeking intention (Goddard 2003; Harewood 2010). Vogel et al. (2005) used more factors in their study to test how social and psychological factors influence college students' help-seeking. Results showed that attitudes towards seeking professional help fully mediated the relationship among self-stigma, self-disclosure, anticipated utility, social norm, social support, and previous therapy and intention to seek help for interpersonal issues. In summary, studies repeatedly showed that help-seeking attitude was a predictor to help-seeking intention and a mediator between some extant factors and help-seeking intention.

Studies had found that subjective norms was a significant predictor of individual's intention to seek professional psychological help. Subjective norms referred to individual beliefs or perceptions about what others (e.g., family, friends, and community members) think about the outcome of a given behavior (Cooper-Patrick et al. 1999). In the TRA model, subjective norms were composed with social norms and individual's motivation to comply with the norms or individual's behavior control ability. But some studies defined subjective norms as perceived social norms, beliefs about what others think about seeking professional help (e.g. Barksdale and Molock 2009). In this study, subjective norms were conceptualized as the second type - the beliefs of what others thought about the behavior of seeking professional psychological help. Individual's behavior control or motivation to comply with others was conceptualized as a different factor.

Many studies reported that female college students were more positive towards seeking psychological help than their male counterparts (Addis and Mahalik 2003; Vogel and Wester 2003). Several studies reported that female students utilized more psychological services than their male counterparts under the same context (Ang et al. 2004; Fischer and Farina 1995). However, other researchers found that 
this gender difference might depend on students' culture background as this difference was not observed in many samples of Asian and American Asian students (Nam et al. 2010). Several studies found that there were no gender differences in attitudes towards psychological help-seeking in the Asian American sample (Atkinson, Lowe, and Matthews 1995; Dadfar and Friedlander 1982). Whether gender plays a role in students' help-seeking intention needs more research.

\section{PURPOSE OF STUDY}

The purpose of this study was to investigate the predictors to Chinese college students seeking psychological help from professionals. In this study, problem severity, subjective norms, behavior control, and gender and family living area were collected to predict students' attitudes and intention towards seeking professional psychological help. Based on the findings from previous studies, a partial mediation model was hypothesized that help-seeking attitudes would partially mediate the relationship between other predictors to help-seeking intention.

\section{METHODS}

Study Design, Participants, Sampling Methods, and Procedure

This study was a cross-sectional survey design (Creswell 2005). Participants in this study were recruited from five universities in Mideast China (two from Guangzhou City and three from Hangzhou City). This study used a convenient sampling method. However, to make the participants better representative, some efforts were done to select the sample by selecting participants from different universities and different majors. Students were recruited from three major fields including social sciences, natural sciences, and applied sciences. As
Chinese college students who are admitted in the same year to the same subject program or major take classes together with their peer groups during the whole college period, the current study utilized each class as the sampling unit. Paper-pencil based surveys were distributed to students at the end of a class. Students were free to choose to participate or not to participate in the study.

All the measures were translated into Chinese with a back-translation strategy. Firstly, the author of this research translated them into Chinese and then another Chinese doctorate student studying in the same field translated them back into English; disagreements were discussed with the author's advisor who was also bilingual in both Chinese and English with experiences of back-translation. The order of all instruments used was counterbalanced across participants.

\section{Measures}

Help-seeking attitudes. The Attitudes Toward Seeking Professional Psychological Help-Short Form (ATSPPHS, Fischer and Farina 1995) was used to measure help-seeking attitudes. ATSPPHS was an abbreviated version of the Attitudes Toward Seeking Professional Psychological Help Scale (Fischer and Turner 1970). Responses to the 10 items on the ATSPPHS were scored on a four-point Likert-type scale ranging from 0 (disagree) to 3 (agree). Higher scores reflected more positive attitudes towards seeking professional help. The current study used the total scale score, which was calculated by adding the responses to the 10 items. A sample item was "I would want to get psychological help if I was worried or upset for a long period of time". This scale had good internal consistency $(\alpha \mathrm{s}=.81-.86$; Berger et al. 2005; Fischer and Farina 1995; Shaffer, Vogel, and Wei 2006). The Cronbach's alpha for the current sample was .64.

Problem severity and help-seeking intention. Problem severity and intentions to seek counseling 
were measured with the Intentions to Seek Counseling Inventory (ISCI, Cash et al. 1975). The ISCI was a 17-item measure. Problems included issues such as relationship difficulties, academic difficulties, personal worries, and drug and alcohol problems. The ISCI included three subscales (see Cepeda-Benito and Short 1998). The three subscales were: interpersonal problems (10 items), academic problems (4 items), and drug/alcohol problems ( 2 items). Cronbach alphas of the three subscales showed good internal reliability: .90 for interpersonal problems, .71 for academic problems, and .86 for drug/alcohol problems (see Cepeda-Benito and Short 1998). Besides the three subscales, there was one single item measuring students' concern about weight problems. The Cronbach's alpha was .97 for the overall scale, .92 for subscale of intention to seek help for interpersonal issues, .80 for subscale of intention to seek help for academic issues, and .64 for subscale of intention to seek help for drug and alcohol abuse.

In this study, ISCI was used to measure both problem severity and intention to seek help. For problem severity, students were asked to rate the agreement level of whether they were experiencing a listed problem at a four-point Likert scale ranging from 1 (totally agree) to 4 (totally disagree). Then students were asked to rate on how likely they would be willing to seek professional help if they were experiencing the problem at four-point Likert scale ranging from 1 (very unlikely) to 4 (very likely). The sum of the total score of first question for all the 17 items was used for the indicator of problem severity with higher score meaning higher level of problem severity. For help-seeking intention, the total score of each subscale was used with higher scores indicating a greater likelihood of seeking counseling for that problem. The score of the single weight-related item was used to measure students' intention to seek help for weight-related problems.

Subjective norms. Subjective norms for seeking help were measured by a single item, "Most people important to me would think that I should seek help from a mental health professional if I were experiencing a persistent personal problem in my life" (Bayer and Peay 1997). Participants were asked to rate this item on a five-point Likert scale ranging from 1 "don't agree" to 5 "totally agree". This item was reverse-coded so that higher score referred to a more negative norm.

Behavior control. Behavior control was measured with three single items: "I think I can decide whether to seek mental health service or not", "Seeking mental health service is dependent on my choice", and "I can seek mental health service if I like to do so". Each item was rated on a five-point Likert scale from 1 "don't agree" to 5 "totally agree". The total score of the three items was used with higher scores indicating lower-level motivation to comply with norms. The Cronbach's alpha in the current sample was .78.

Family living area and gender. Family living area was measured with one question: "Where are you from? A) Urban area, B) rural area". Urban area was coded as 1 and rural area was coded as 0 . Male students were coded as 1 and female students were coded as 0 .

\section{Data Analysis Strategies}

Frequencies, means, and standard deviations were computed for all the socio-economic and demographic variables with SPSS software for windows, to show a full picture of the participants. Structural equation modeling (SEM) with Mplus 5.2 software (L. K. Muthen and B. O. Muthen 2007) was used to analyze the relationship between the factors and help-seeking intention.

\section{RESULTS}

\section{Response Rate}

The questionnaires were distributed to a total of 1,850 students. Altogether 1,670 students returned the questionnaires. The response rate was $90.27 \%$. The 
unfinished questionnaires and those with contradictory answers to the polygraph items were taken out, which resulted in a final 1,408 effective questionnaires. The effect rate was $76.11 \%$. Fifteen percent of the remained 1,408 questionnaires were checked by hand with entry accuracy. The accuracy rate was $92.7 \%$, indicating a high-level of entry accuracy.

\section{Means, Standard Deviations, Skewness, Kurtosis, and Correlations}

Table 1 showed means, standard deviations, skewness, and kurtosis of each variable. Table 2 showed zero-order correlations between the independent variables and the dependent variables of help-seeking attitudes and help-seeking intention. The zero-order correlations also showed that problem severity, social norms, behavior control, and family living area and gender all related to either attitudes or intention towards seeking professional help.

Attitudes towards seeking professional psychological help. Scores on the ATSPPHS could range from 0 to 30. In this sample, it ranged from 0 to 29 . The mean ATSPPHS score was $16.42(\mathrm{SD}=4.36$, Mode $=16.00$, and Median $=16.00$ ), indicating a moderate attitude.

Intention to seek professional psychological help. The mean of the help-seeking intention scale was $33.80(\mathrm{SD}=10.09)$, and the range was 17 to 68 , indicating a moderate intention level of willingness to seek psychological help. The mean was much lower than the mean (45.86 with a 16.45 standard deviation) reported by Cepeda-Benito and Short (1998) based on 732 psychology major students.

Normality. As the maximum-likelihood procedure the authors planned to use to test their hypothesized

Table 1. Descriptive Statistics for All Variables

\begin{tabular}{llllll}
\hline & $\mathrm{N}$ & Mean & $\mathrm{SD}$ & Skewness & Kurtosis \\
\hline Gender & 1,281 & .42 & .49 & .33 & -1.9 \\
Living area & 1,361 & .62 & .49 & -.5 & -1.75 \\
Help-seeking attitudes & 1,346 & 16.42 & 4.36 & -.18 & .21 \\
Problem severity & 1,327 & 33.83 & 7.21 & -.1 & .01 \\
Behavior control & 1,370 & 6.44 & 1.97 & .93 & 2.46 \\
Subjective norms & 1,371 & 2.89 & .9 & .11 & -.3 \\
Help-seeking knowledge & 1,359 & 3.99 & 1.23 & -.48 & .25 \\
Help-seeking intention for interpersonal problems & 1,284 & 33.8 & 10.09 & .05 & -.54 \\
Help-seeking intention for academic problems & 1,347 & 8.67 & 2.69 & -.02 & -.43 \\
Help-seeking intention for drug/alcohol problems & 1,353 & 3.33 & 1.36 & .77 & -.1 \\
Help-seeking intention for weight problems & 1,370 & 1.79 & .74 & .53 & -.46 \\
Valid N (listwise) & 919 & & & & \\
\hline
\end{tabular}

Table 2. Correlations Between Independent and Dependent Variables

\begin{tabular}{llllll}
\hline Variables & HSA & HSI-A & HIS-I & HIS-D & HIS-W \\
\hline Gender & $-.16^{* * *}$ & $-.08^{* *}$ & $-.09^{* *}$ & .01 & -.05 \\
Family living area & $-.05^{*}$ & .02 & .04 & .01 & -.01 \\
Problem severity & $-.08^{* *}$ & $.46^{* * *}$ & $.48^{* * *}$ & $.28^{* * *}$ & $.27^{* * *}$ \\
Subjective norms & $-.23^{* * *}$ & $-.14^{* * *}$ & $-.13^{* * *}$ & $-.09^{* * *}$ & $-.07^{* *}$ \\
Behavior control & $-.13^{* * *}$ & $.07^{* *}$ & .05 & $.08^{* *}$ & $.08^{* *}$ \\
\hline
\end{tabular}

Notes: ${ }^{*} p<.05,{ }^{* *} p<.01,{ }^{* * *} p<.001$. HSA = help-seeking attitudes, HIS-A = help-seeking intention for academic problems, HIS-I = help-seeking intention for interpersonal problems, HIS-D = help-seeking intention for drug/alcohol problems, HIS-W $=$ help-seeking intention for weight-related problems. 
model assumes normality, skew and kurtosis statistics for the main variables and scales were calculated and were reported in Table 1. There were three variables with kurtosis value over an absolute value of 2.0. Most of the rest variables had an absolute skewness and kurtosis value smaller than 1.0, indicating that the data did not violate the assumptions of normality and were deemed appropriate for use with the planned parametric statistics.

\section{The SEM Model}

The present study investigated Chinese college students' professional psychological help-seeking intention and its association with some social and psychological factors. Help-seeking attitudes were hypothesized as mediator between other predictors and help-seeking intention. To cross-validate the model, the data were randomly divided into two sets, and the model was tested with each data set. The fit indices for the analysis of the two sets of data were shown in Table 3. Parameter estimates of the two sets of data were shown in Tables 4 and 5, respectively. The overall significant relations between the antecedent variables and help-seeking intention were presented in Figure 1.

The SEM models yielded very similar results for the two sets of data. The chi-square values across the two sets of data were significant $\left(\chi^{2}=83.369, \mathrm{df}=20\right.$, $p=.0000$, for half- 1 data; $\chi^{2}=50.487, \mathrm{df}=20$, $p=.0002$, for half- 2 data), indicating that the model did

Table 3. Fit Indices for the SEM Model

\begin{tabular}{lll}
\hline Fit indices & Half-1 data & Half-2 data \\
\hline Chi-square & 83.369 & 50.487 \\
$\mathrm{df}$ & 20 & 20 \\
$\mathrm{~N}$ & 534 & 535 \\
$\mathrm{P}$ & .0000 & .0002 \\
$\mathrm{CFI}$ & .952 & .978 \\
TLI & .917 & .961 \\
RMSEA & .077 & .053 \\
SRMR & .031 & .023 \\
\hline
\end{tabular}

Table 4. Parameter Estimates of the SEM Model for Half-1 Data Set

\begin{tabular}{lllll}
\hline & Factor loading & Error & T-value & R-square \\
\hline To help-seeking intention from & & & & .25 \\
\hline Gender & -.06 & .10 & -1.45 & \\
Living area & .06 & .10 & 1.45 & 5.48 \\
Help-seeking attitudes & $.22^{* * *}$ & .01 & 10.68 & \\
Problem severity & $.49^{* * *}$ & .01 & -.62 & .08 \\
Subjective norms & -.03 & .06 & -.01 & \\
Behavior control & -.01 & .03 & & \\
\hline To help-seeking attitudes from & & & -2.63 & \\
Gender & $-.11^{* *}$ & .37 & -1.98 & \\
Living area & $-.08^{*}$ & .38 & -5.32 & -1.41 \\
Problem severity & -.07 & .03 & .20 & \\
Subjective norms & $-.22^{* * *}$ & .12 & \\
Behavior control & -.06 & & & \\
\hline
\end{tabular}

Note: ${ }^{*} p<.05,{ }^{* *} p<.01,{ }^{* * *} p<.001$. 
Table 5. Parameter Estimates of the SEM Model for Half-2 Data Set

\begin{tabular}{lllll}
\hline & Factor loading & Error & T-value & R-square \\
\hline To help-seeking intention from & & & & .38 \\
\hline Gender & -.02 & .10 & -.48 & \\
Living area & .02 & .10 & .50 & 7.85 \\
Help-seeking attitudes & $.31^{* * *}$ & .01 & 12.88 & \\
Problem severity & $.53^{* * *}$ & .01 & -2.15 & .12 \\
Subjective norms & $-.08^{*}$ & .06 & 1.15 & \\
Behavior control & .04 & .03 & -3.77 & .28 \\
\hline To help-seeking attitudes from & & & -1.32 & \\
\hline Gender & $-.16^{* *}$ & .37 & -6.47 & \\
Living area & .01 & .38 & .03 & \\
Problem severity & -.05 & .20 & .12 & \\
Subjective norms & $-.27^{* * *}$ & $.12^{* *}$ & & \\
Behavior control & & .86 & \\
\hline
\end{tabular}

Note: ${ }^{*} p<.05,{ }^{* *} p<.01,{ }^{* * *} p<.001$.

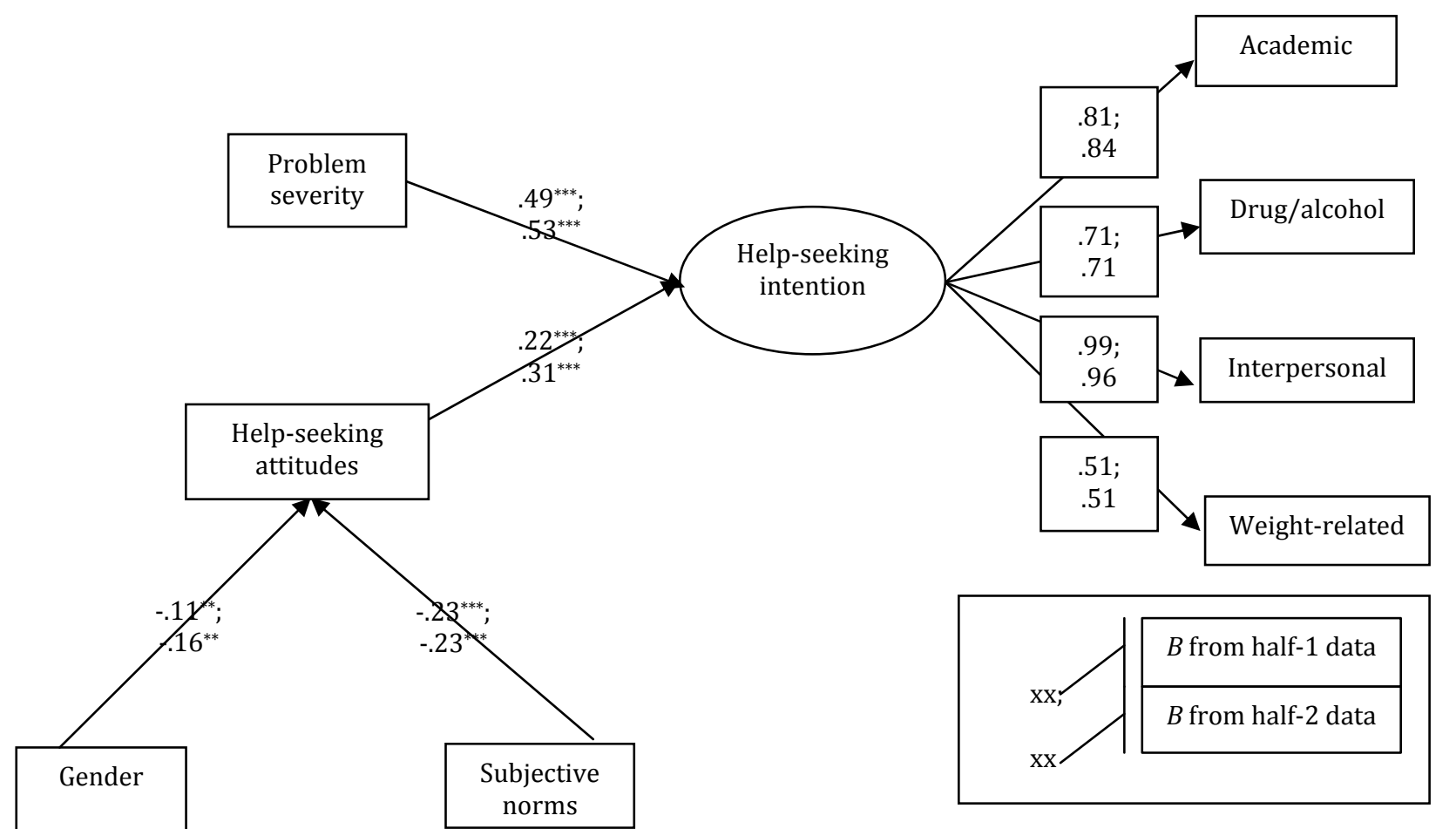

Figure 1. Structural Equation Model and Factor Loadings.

Note: Only variables with significant factor loadings on both sets of data were shown for clarity.

not fit the data. However, the value of the ratio between chi-square and the degree of freedom were both smaller than 5 (for half- 1 data, chi-square/df $=$ 4.17; for half-2 data, chi-square/ $\mathrm{df}=2.52$ ), indicating a good fit of the data. Other close fit indices also yielded good fit results: $\mathrm{CFI}=.952$ and .978 for half-1 and half-2 data sets, respectively; TLI $=.917$ and .961 for half-1 data set and half-2 data set, respectively; all the CFI and TLI values were bigger than .90. RMSEA $=.077$ and .053 , both were smaller than .08 ; SRMR 
$=.031$ and .023 , both were smaller than .05 . All of these fit indices showed that the model was fit to the data.

Significant direct paths from half-1 data showed that problem severity and help-seeking attitudes had a significant direct effect on help-seeking intention through help-seeking intention $(\beta=.49, t=10.68, p$ $<.001 ; \beta=.22, t=-5.48, p<.001$, respectively). Gender, subjective norms, and family living area showed significant indirect effects on help-seeking intention through help-seeking attitudes (for gender, $\beta$ $=-.11, t=-2.63, p<.01$; for subjective norms, $\beta=$ $-.22, t=-5.32, p<.001$; and for family living area, $\beta=$ $-.08, t=-1.98, p<.05)$.

The result from half- 2 data validated direct effects from problem severity and help-seeking attitudes to help-seeking intention (for problem severity, $\beta=.53, t$ $=12.88, p<.001$; for help-seeking attitudes, $\beta=.31, t$ $=7.85, p<.001)$. The results also validated the indirect effects from gender and subjective norms to help-seeking intention through help-seeking attitudes (for gender, $\beta=-.16, t=-3.77, p<.001$; for subjective norms, $\beta=-.27, t=-6.47, p<.001$ ), but did not validate the effect of family living area. Besides, subjective norms showed a significant direct effect to help-seeking intention $(\beta=-.08, t=-2.15, p<.05)$, but it was not shown as significant effect in half-1 data $(\beta=-.03, t=-.62, p>.05)$. Behavior control showed a significant indirect effect from help-seeking to help-intention $(\beta=-.12, t=-2.86, p<.01)$, however it was not supported in half- 1 data $(\beta=-.06, t=-1.41$, $p>.05)$.

\section{CONCLUSIONS}

In an effort to improve the understanding of mainland Chinese college students' intention to seek psychological help, the current study proposed that the independent factors would influence college students' professional help-seeking intention both directly and indirectly through help-seeking attitudes. The results showed that among the factors examined, problem severity and help-seeking attitudes directly predicted help-seeking intention, while gender and subjective norms had significant effect on college students' professional psychological help-seeking intention through help-seeking attitudes. Behavior control and family living area showed inconsistent effects on college students' help-seeking attitudes or intention. More research needs to be done to further examine what role they play in students' help-seeking process. Overall, the model explained $25 \%$ and $38.0 \%$ (for half- 1 and half- 2 data sets, respectively) of the variances of help-seeking intention.

\section{Discussion}

The finding from the current study supported previous findings that problem severity was not a direct predictor of help-seeking intention (Nagai 2010). This relationship was not mediated by help-seeking attitudes. Students with more severe problems or concerns showed stronger intention to seek professional psychological help than those with less severe problems or concerns. Help-negation effect was not found in the current study, possibly because help-negation effect mainly existed in serious mental problems such as depression and suicide intention, while the problem severity level of the current student sample was not high enough.

Help-seeking attitudes were found as a full mediator (Bagley 2011; Harewood 2010), as well as a partial mediator (Pietruszka 2007; Vogel et al. 2005) in previous studies. In this study, help-seeking attitudes mediated the effects from gender and subjective norms to help-seeking intention. Compared with male students, female students showed more favorite attitudes towards seeking professional help. This was consistent with many previous studies (Addis and Mahalik 2003; Vogel and Wester 2003). The effect of subjective norms was consistent with findings in the studies of both Barksdale and Molock (2009) and Vogel et al. (2005). These results indicated 
the importance of surrounding people's ideas on individual's help-seeking attitudes.

Overall, the current study found the unique power of problem severity and help-seeking attitudes in predicting students' intention to seek professional help. However, the mean of help-seeking attitudes was at a moderate level, which implicated that students might not be really willing to seek professional help due to personal stigma and social norms, although they knew they should rationally do so when the problem got serious.

\section{Implications}

Although when concerns or problems become severe enough, students might decide to seek professional help, the attitudes towards using professional service were only at a moderate level. Therefore university educators and counselors can work on promoting students' positive attitudes towards seeking professional help. The beliefs about what others think about seeking professional help (subjective norms) influence students' attitudes towards seeking professional help. If students perceived more negative norms, they were less likely to seek help. University educators and counselors can strengthen the education of mental health knowledge and the benefits of professional services, as well as enhance the advocacy of seeking professional help.

\section{Limitations}

This study used a convenient sampling and it should be cautious to generalize the results to other population. Although multiple sampling sources and the cross-test statistical methods enhance its validity, it is worth noting that the results come from two convenient samples. The limitation lends itself to the future research direction. A random sample which is representative to Chinese college students' body will provide better implications for the literature.

In summary, research on Chinese students' help-seeking behavior is in its beginning. Studies were sparse. Effects of many of the correlated factors as identified in Western cultures need empirical support in Chinese college students sample. The current study added to the literature by providing evidence-based research. It also helped to generalize the theory of reasoned action across culture. The research on students' help-seeking behavior is timely in today's China which has approximately 23 million college students, the largest in the world (Yang 2005).

\section{References}

Addis, M. E. and J. R. Mahalik. 2003. "Men, Masculinity, and the Contexts of Help Seeking." American Psychologist 58(1):5-14.

Anderson, R. M. 1995. "Revisiting the Behavioral Model and Access to Medical Care: Do It Matter?" Journal of Health and Social Behavior 36(March):1-10.

Ang, R. P., K. M. Lim, A. G. Tan, and T. Y. Yau. 2004. "Effects of Gender and Sex Role Orientation on Help-Seeking Attitudes." Current Psychology 23(3):203-214.

Atkinson, D. R., S. Lowe, and L. Matthews. 1995. "Asian-American Acculturation, Gender, and Willingness to Seek Counseling." Journal of Multicultural Counseling and Development 23(3):130-138.

Bagley, K. 2011. "Cross-Racial Comparison of Cognitive Factors Influencing Help-Seeking.” Doctoral dissertation, George Mason University.

Barksdale, C. L. and S. D. Molock. 2009. "Perceived Norms and Mental Health Help Seeking Among African American College Students." The Journal of Behavioral Health Services \& Research 36(3):285-299.

Bayer, J. K. and M. Y. Peay. 1997. "Predicting Intentions to Seek Help From Professional Mental Health Services." Australian and New Zealand Journal of Psychiatry 31(4):504-513.

Benson, P. L. 1990. "Help-Seeking for Alcohol and Drug Problems: To Whom Do Adolescents Turn?" Journal of Adolescent Chemical Dependency 1(1):83-94.

Berger, J. M., R. Levant, K. K. McMillan, W. Kelleher, and A. Sellers. 2005. "Impact of Gender Role Conflict, Traditional Masculinity Ideology, Alexithymia, and Age on Men's Attitudes Towards Psychological Help Seeking." Psychology of Men and Masculinity 6:73-78.

Boldero, J. and B. Fallon. 1995. "Adolescent Help-Seeking: What Do They Get Help for and From Whom?" Journal of Adolescence 18(2):193-209. 
Carlton, P. A. and F. P. Deane. 2000. "Impact of Attitudes and Suicidal Ideation on Adolescents' Intentions to Seek Professional Psychological Help." Journal of Adolescence 23(1):35-45.

Cash, T. F., P. J. Begley, D. A. McCown, and B. C. Weise. 1975. "When Counselors Are Heard but not Seen: Initial Impact of Physical Attractiveness." Journal of Counseling Psychology 22(4):273-279.

Cepeda-Benito, A. and P. Short. 1998. "Self-concealment, Avoidance of Psychological Services, and Perceived Likelihood of Seeking Professional Help." Journal of Counseling Psychology 45(1):58-64.

Chang, H. 2008. "Help-Seeking for Stressful Events Among Chinese College Students in Taiwan: Roles of Gender, Prior History of Counseling, and Help-Seeking Attitudes." Journal of College Student Development 49(1):41-51.

Cooper-Patrick, L., J. J. Gallo, N. R. Powe, D. S. Steinwachs, W. W. Eaton, and D. E. Ford. 1999. "Mental Health Service Utilization by African Americans and Whites: The Baltimore Epidemiologic Catchment Area Follow-up." Medical Care 37(10):1034-1045.

Cramer, K. M. 1999. "Psychological Antecedents to Help-Seeking Behavior." Journal of Counseling Psychology 46(3):381-387.

Creswell, J. W. 2005. Educational Research: Planning, Conducting, and Evaluating Quantitative and Qualitative Research. Upper Saddle River, N.J.: Merrill.

Dadfar, S. and M. L. Friedlander. 1982. "Differential Attitudes of International Students Toward Seeking Professional Psychological Help." Journal of Counseling Psychology 29(3):335-338.

Deane, F. P., C. J. Wilson, and J. Ciarrochi. 2001. "Suicidal Ideation and Help-Negation: Not Just Hopelessness or Prior Help.” Journal of Clinical Psychology 57(7):901-914.

Fischer, E. H. and A. Farina. 1995. "Attitudes Toward Seeking Professional Psychology Help: A Shortened Form and Considerations for Research." Journal of College Students Development 36:368-373.

Fischer, E. H. and J. L. Turner. 1970. "Orientations to Seeking Professional Help: Development and Research Utility of an Attitude Scale." Journal of Consulting and Clinical Psychology 35(1):79-90.

Fishbein, M. and I. Ajzen. 2010. Predicting and Changing Behavior: The Reasoned Action Approach. New York: Psychology Press.

Goddard, E. 2003. "Using the Theory of Reasoned Action to Predict Undergraduate and Graduate Student Help-Seeking Intentions: The Effects of Attitudes, Subjective Norms, 'Referral of Others', and Gender." Dissertation Abstracts International 64(2-B):963.

Goh, M., B. Xie, K. Wahl, G. Zhong, F. Lian, and J. Romano.
2007. "Chinese Students' Attitudes Toward Seeking Professional Psychological Help.” International Journal for the Advancement of Counseling 29(3-4):187-202.

Harewood, J. E. 2010. "Social and Personal Determinants of Help-Seeking Intentions Among Black College Students." Doctoral dissertation, State University of New York at Albany.

Kelly, A. E. and J. A. Achter. 1995. "Self-concealment and Attitudes Toward Counseling in University Students." Journal of Counseling Psychology 42(1):40-46.

Kim, J. 2009. "Relationship of Gender Role Conflict and Acculturation to Willingness to Seek Psychological Help Among Asian American and European American Men.” Doctoral dissertation, University of Southern California.

Ministry of Education. 2001. Views of Ministry of Education on Strengthening College Students' Mental Health Education. Retrieved (http://www.gov.cn/gongbao/content/2002/cont ent_61930.htm).

Muthen, L. K. and B. O. Muthen. 2007. Mplus Statistical Analysis With Latent Variables: A User's Guide. 5th ed. Los Angeles, CA: Muthen \& Muthen.

Nagai, S. 2010. "Determinants of the Help-Seeking Intentions of University Students: Relations Among Main Factors." Japanese Journal of Educational Psychology 58(1):46-56.

Nam, S. K., H. J. Chu, M. K. Lee, J. H. Lee, N. Kim, and S. M. Lee. 2010. "A Meta-Analysis of Gender Differences in Attitudes Toward Seeking Professional Psychological Help." Journal of American College Health 59(2):110-116.

Pietruszka, T. D. 2007. "Barriers to College Student Utilization of Mental Health Services: A Path Model." Doctoral dissertation, University of Memphis.

Pugh, J. 2002. "Help Seeking and Personality Among College Students." Dissertation Abstracts International: Section B: The Sciences and Engineering 62:387.

Shaffer, P. A., D. L. Vogel, and M. Wei. 2006. "The Mediating Roles of Anticipated Risks, Anticipated Benefits, and Attitudes on the Decision to Seek Professional Help: An Attachment Perspective." Journal of Counseling Psychology 53(4):442-452.

Vogel, D. L. and S. R. Wester. 2003. "To Seek Help or not to Seek Help: The Risks of Self-disclosure." Journal of Counseling Psychology 50(3):351-361.

Vogel, D. L., G. W. Nathaniel, and S. Haake. 2006. "Measuring the Self-stigma Associated With Seeking Psychological Help." Journal of Counseling Psychology 53(3):325-337.

Vogel, D. L., S. R. Wester, M. Wei, and G. A. Boysen. 2005. "The Role of Outcome Expectations and Attitudes on Decisions to Seek Professional Help." Journal of Counseling Psychology 52(4):459-470.

Wong, S. J. 2010. "Comparisons of Psychological Help 
Seeking Between Asian American and Caucasian College Students." Doctoral dissertation, George Mason University. Yakunina, E. S., J. R. Rogers, C. A. Waehler, J. L. Werth, Jr. 2010. "College Students' Intentions to Seek Help for Suicidal Ideation: Accounting for the Help-Negation Effect." Suicide and Life-Threatening Behavior 40(5):438-450.

Yang, D. P. 2005. "The Largest Population of College Students in the World, the Decreasing Education Quality." Xinjing Newspaper, December 23. Retrieved (http://education.163. com/06/0522/09/2HNFGIJ300291MUF.html).

\section{Bios}

Haiping Wang, Ph.D., assistant professor, Department of Social Work, East China Normal University, China; research fields: adolescent mental health, positive developing, women study, marriage and family therapy.

Yan Ruth Xia, Ph.D., professor, Department of Child, Youth and Family Studies, University of Nebraska-Lincoln, USA; research fields: adolescent mental health, child development, marriage and family therapy. 